\title{
IMMUNONUTRITION WITH GLUTAMINE IN ICU PATIENTS
}

\author{
REKHA DAS ${ }^{1}$, SIDHARTH SRABAN ROUTRAY2* , AMIT PRADHAN ${ }^{3}$, SNIGDHA IPSITA ${ }^{2}$
}

${ }^{1}$ Department of Anaesthesiology, Pain and Palliative Care, Acharya Harihar Regional Cancer Research Centre, Cuttack, Odisha, India. ${ }^{2}$ Department of Anaesthesiology, Shrirama Chandra Bhanj Medical College, Cuttack, Odisha, India. ${ }^{3}$ Department of Anaesthesiology, Kalinga Institute of Medical Sciences, Bhubaneswar, Odisha, India. Email: drkitusraban@gmail.com

Received: 07 April 2017, Revised and Accepted: 05 May 2017

\section{ABSTRACT}

Objective: Endogenous production of glutamine may be reduced during critical illness. The shortage of glutamine is reflected as a decrease in plasma concentration, which is a prognostic factor for outcome in sepsis. Therefore, we have studied the effect of enteral or parenteral glutamine therapy on biochemical parameters and the hospital stay of critically ill patients.

Methods: A total of 66 critically ill patients aged 18-70 years, admitted to central and medical intensive care unit of a tertiary care hospital were randomly divided into three equal groups; 22 in each group: Group 1 (control group) received no glutamine, Group 2 received oral glutamine $0.5 \mathrm{~g} / \mathrm{kg} / \mathrm{d}$ for 5 days, and Group 3 received parenteral glutamine $0.5 \mathrm{~g} / \mathrm{kg} / \mathrm{d}$ by intravenous infusion for 5 days. All patients received glutamine-free tube feed throughout the study period. Total leukocyte count (TLC), total lymphocyte count, total protein and serum albumin, serum lactate, and sequential organ failure assessment (SOFA) score were recorded on each day for 7 days and were compared.

Results: Decrease in the TLC and increase in lymphocyte count was most evident in Group 3 compared to Groups 2 and 1 which was statistically significant. Decrease in serum lactate and increase in serum protein and albumin was maximum in Group 3 compared to Groups 1 and 2 which was statistically significant. The mean duration of hospital stay of Group 3 was the least followed by Groups 2 and 1 which was statistically not significant. There was an improvement in SOFA score in all the three groups.

Conclusion: Parenteral glutamine in a dose of $0.5 \mathrm{~g} / \mathrm{kg} / \mathrm{d}$ was more potent than oral glutamine in improving the biochemical parameters. The duration of hospital stay was similar in all the groups after treatment.

Keywords: Glutamine, Serum lactate, Lymphocyte.

(C) 2017 The Authors. Published by Innovare Academic Sciences Pvt Ltd. This is an open access article under the CC BY license (http://creativecommons. org/licenses/by/4. 0/) DOI: http://dx.doi.org/10.22159/ajpcr.2017.v10i8.18984

\section{INTRODUCTION}

Glutamine is a nonessential amino acid that can become conditionally essential under catabolic states such as critical illness and burns [1]. It is synthesized by the enzyme glutamine synthetase from glutamate and ammonia predominantly by muscle but also in small amounts by the lung and brain. It plays a central role as a fuel source for enterocytes, lymphocytes, and other rapidly dividing cells of the immune system [2]. Although glutamine and glutamate comprises $10-20 \%$ of dietary protein, no net absorption occurs as these amino acids undergo significant metabolism in the enterocyte, serving as a major respiratory fuel [3]. As dietary glutamine supplies are exhausted, the enterocytes begin to rely on circulating glutamine. Systemic glutamine availability is determined by the balance of endogenous glutamine production (mainly in muscular tissue) and its use by glutamine consuming organs (gut, kidney, liver, and the immune system) [4]. Several studies have shown that in catabolic patients, the endogenous production of muscular glutamine is increased while the plasma levels or glutamine are decreased, indicating elevated glutamine needs. Studies have shown that low plasma glutamine values on admission are related to increased mortality [5]. These findings are the rationale for the use of glutamine supplementation in the intensive care unit (ICU) patients to meet the demand for improvement in protein synthesis, modulation of the immune system, reduction of oxidative stress, and preservation of the gut barrier. Glutamine is safe up to $40 \mathrm{~g}$ /day with either enteral or parenteral route. Still it is not clear which route is better [6,7]. Some studies are there stating parenteral nutrition may be better than enteral nutrition in terms of clinical outcome in patients getting parenteral nutrition. However, in patients getting enteral nutrition, studies differ whether enteral or parenteral route to be preferred for glutamine administration [8-10]. The objective of this study was to evaluate the effect of parenteral glutamine and oral glutamine in critically ill patients. The primary objective of our study was to measure changes in the biochemical parameters such as total leukocyte count (TLC), lymphocyte count, serum protein and serum albumin and serum lactate levels. The secondary objective was to measure the effect on duration of hospital stay and mortality.

\section{METHODS}

This was a prospective randomized, single-blinded, placebo controlled study done at central and medical ICU, SCB Medical College, Cuttack, between September 2014 and October 2016 after due permission from the hospital ethical committee. This study was done on 66 patients of age 18-70 years who were critically ill and accepting standard enteral feeds. Reason of ICU admission, i.e., medical reasons (respiratory failure, CVA), elective surgery (major abdominal surgery, major thoracic surgery, and spine surgery), or emergency surgeries (perforation peritonitis, polytrauma). Patients with APACHE II score from 10 to 20 and expected stay in ICU>7 days were included in this study. Patients having renal failure, pregnancy, hepatic failure, patients receiving cytotoxic drugs, steroids and radiation therapy, unable to tolerate enteral feed within $72 \mathrm{hrs}$ of admission and patients with gastrointestinal bleeding or intestinal obstruction were excluded from the study. The patients were divided into three groups of 22 each. Randomization was done using the random number table, and concealment was done by the sealed envelope technique. Demographic variables were age, gender, and weight. APACHE II score at the time of admission, baseline hematological counts, serum electrolytes, serum protein, albumin, bilirubin, lactate, serum urea, and creatinine levels were recorded. On admission to the ICU, after adequate resuscitation, confirmation of hemodynamic stability, gut integrity and acceptance of test feed, enteral nutrition 
was started via the nasogastric tube (in semi-recumbent position) preferably within $24 \mathrm{hrs}$ of ICU admission. All the patients received the standard enteral feed in the ICU $30 \mathrm{kcal} / \mathrm{kg} /$ day including carbohydrate $(70 \%)$, fat $(30 \%)$, and protein $1.5 \mathrm{~g} / \mathrm{kg} /$ day in accordance with the enteral feeding guidelines. The study groups received the following supplementation: Group 1-(Control): Received standard enteral feed along with $100 \mathrm{ml}$ normal saline infusion. Group 2-(Enteral glutamine): Received standard enteral feed along with $0.5 \mathrm{~g} / \mathrm{kg} /$ day of glutamine along with $100 \mathrm{ml}$ of normal saline infusion. Group 3-(Parenteral glutamine): Received standard enteral feed along with $0.5 \mathrm{~g} / \mathrm{kg} /$ day of IV glutamine as an infusion. The glutamine supplementation was given for 7 days after which the patients continued to receive the standard enteral feed. The sedation, acid suppression, antibiotics, fluid therapy, insulin therapy, and weaning were done as per the ICU protocol in all the patients. The TLC, lymphocyte count, total platelet count, serum protein, serum albumin, serum urea, serum creatinine, serum bilirubin, serum lactate, and blood glucose were sent every morning at around $8 \mathrm{am}$. Sequential organ failure assessment (SOFA) score was assessed every day from day 1 to day 7 .

The primary outcomes studied were the effect of glutamine supplementation on serum lactate, TLC, total serum lymphocyte count, serum protein and albumin and SOFA score. The secondary outcomes studied were the length of stay (LOS) in ICU, days of mechanical ventilation and mortality in ICU. The change in serum lactate level was used as primary endpoints. The analysis determined that 25 patients per group would provide $80 \%$ power to determine the minimal detectable difference of $0.5 \mathrm{meq} / \mathrm{l}$ of serum lactate between glutaminesupplemented parenteral nutrition and standard nutrition. Statistical analysis was performed suing SPSS 20 software. The values were described as mean \pm standard deviation if normally distributed and as median and interquartile range if the distribution is skewed. Age, weight, and APACHE II score were analyzed by ANOVA. The discrete variables, i.e., sex and mortality were analyzed using Chi-square or Fischer's exact test. The biochemical and clinical outcome parameters were analyzed by Kruskal-Wallis test. Paired analysis was performed by Mann-Whitney U-test between groups. Friedman test was used to analyze changes within a group. $\mathrm{p}<0.05$ was considered significant. $\mathrm{p}<0.001$ was considered as statistically highly significant.

\section{RESULTS}

There was no statistical difference with respect to age, gender, body mass index, and APACHE I score among three groups.

The mean APACHE II score in the control group was 14.45 \pm 4.22 , enteral group was $13.68 \pm 2.8$ and parenteral group was $14.2 \pm 4.16$, and there was no statistically significant difference among the three. There was no statistically significant difference regarding no of days of mechanical ventilation, serum bilirubin, serum lactate, serum creatinine, and blood glucose among the three groups. Furthermore, SOFA score was comparable within three groups (Table 1).

The improvement in laboratory parameters within each group was analyzed by comparing the median values of each parameter on days 1, 4 and 7 by Friedman test. In Group 1, there was no significant change in serum lactate level. There was a significant improvement in SOFA score in Group 1 between days 1 and 7, other values being statistically insignificant (Table 2).

In Group 2, the lymphocyte count increased appreciably from day 1 to day 7 but did not attain statistical significance. Serum albumin also increased markedly in Group 2 but not statistically significant. There was no significant change in serum lactate level, but there was a statistically significant improvement in SOFA score within the group in 7 days (Table 3).

In Group 3, there was statistically significant improvement in serum lactate, leukocyte count, lymphocyte count, and serum albumin and protein from day 1 to day 7. Improvement in SOFA score from day 1 to day 7 was statistically highly significant (Table 4).
The mortality in the ICU between the groups was analyzed suing Fischer's exact test. The mortality rate among the three groups was not statistically significant. The mortality rate in the parenteral group was lesser when compared to the control or enteral group. However, this did not attain any statistical significance (Fig. 1).

The LOS in ICU and duration of mechanical ventilation was analyzed using Kruskal-Wallis test. The median LOS was 19.5 days in Group 1, 17 days in Group 2, and 19 days in Group 3 and no statistical significance was observed among the groups (Fig. 2).

\section{DISCUSSION}

Nutrition has an important role in all ICU patients to combat the increased demand, maintain the basal function as well as to increase the immunological response. Enteral route is preferred due to its efficacy, safety, beneficial effect on gut function, and reduced side effects as compared to the parenteral route. It should be started within $24 \mathrm{hrs}$ of ICU admission in patients who can tolerate oral feeding. Glutamine as an immune nutrient is recommended mainly in classes of patients such as burns and trauma. The benefit is however subjective depending on the route, dose, severity of illness, and other comorbidities. Over the years, many studies examining glutamine in ICU patients have presented controversial results. Recently, concluded redox study and Signet study has questioned the safety and efficacy of glutamine in critically ill patients. However, several published meta-analyses have initially showed a significant reduction in mortality and infectious morbidity. It is not easy to obtain a clear answer to the above-quoted question, as the critically ill population is a heterogeneous one. Studies often mix patients with different pathologies and prognosis, as well as include distinct routes of administration and the use of different doses than those recommended by the guidelines, thus giving mixed results, especially when compared to a metanalysis $[11,12]$. Hence, we studied the effect of enteral and parenteral glutamine supplementation in critically ill patients from a mixed medical and surgical ICU. The optimal dose of glutamine by enteral route is still unknown, but studies

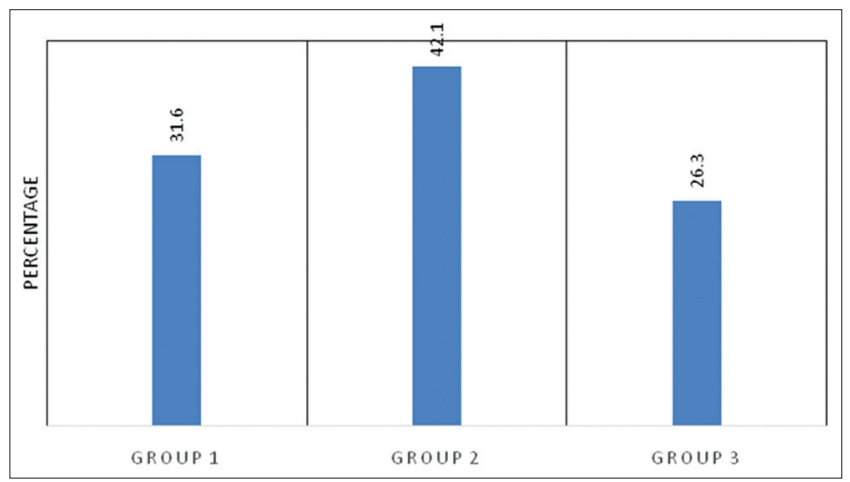

Fig. 1: Distribution of mortality among different groups

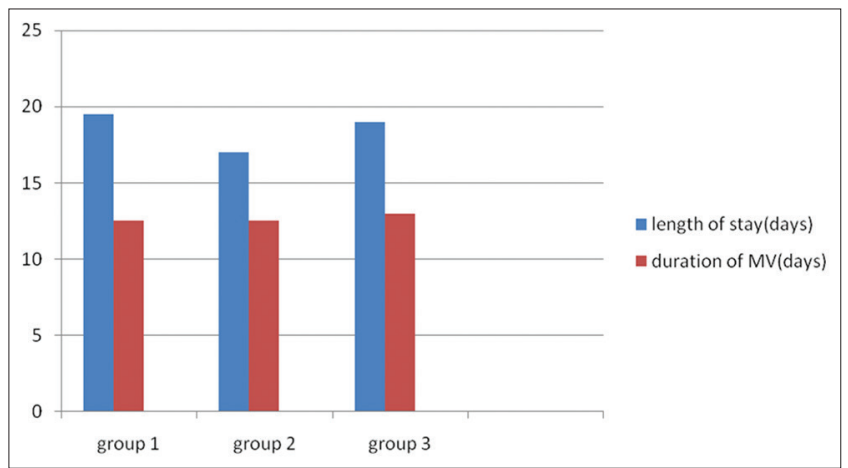

Fig. 2: Comparison of length of stay in intensive care unit and days of mechanical ventilation 
Table 1: Comparison of baseline characteristics among different groups $(n=22)$

\begin{tabular}{|c|c|c|c|c|}
\hline Variables & Group 1 (n-22) & Group 2 (n-22) & Group 3 (n-22) & $\mathbf{p}$ \\
\hline Age $(y)$ & $60.5 \pm 5.4$ & $62.8 \pm 2.8$ & $58.6 \pm 6.4$ & $\mathrm{p}>0.05$ \\
\hline Gender $(\mathrm{M} / \mathrm{F})$ & $12 / 10$ & $13 / 9$ & $15 / 7$ & $\mathrm{p}>0.05$ \\
\hline BMI $\left(\mathrm{kg} / \mathrm{m}^{2}\right)$ & $28.1 \pm 1.4$ & $25.9 \pm 2.1$ & $26.7 \pm 1.9$ & $\mathrm{p}>0.05$ \\
\hline Number of patients on mechanical ventilation & 4 & 4 & 3 & $\mathrm{p}>0.05$ \\
\hline Serum lactate $(\mathrm{mmol} / \mathrm{l})$ & $3.5 \pm 1.1$ & $3.9 \pm 1.3$ & $3.4 \pm 0.9$ & $\mathrm{p}>0.05$ \\
\hline Serum bilirubin (mg/dl) & $1.6 \pm 0.6$ & $1.8 \pm 0.4$ & $1.4 \pm 0.7$ & $\mathrm{p}>0.05$ \\
\hline Serum creatinine (mg/dl) & $0.8 \pm 0.2$ & $0.9 \pm 0.3$ & $0.8 \pm 0.1$ & $\mathrm{p}>0.05$ \\
\hline APACHE II score & $14.45 \pm 4.22$ & $13.68 \pm 2.8$ & $14.2 \pm 4.16$ & $\mathrm{p}>0.05$ \\
\hline SOFA score & $4.9 \pm 0.8$ & $5.1 \pm 0.6$ & $5.4 \pm 0.9$ & $\mathrm{p}>0.05$ \\
\hline
\end{tabular}

BMI: Body mass index

Table 2: Comparison of parameters in Group 1

\begin{tabular}{llll}
\hline Variables & Day $\mathbf{1}$ & Day 4 & Day 7 \\
\hline Total leukocyte count (thousand $\left./ \mathrm{cm}^{2}\right)$ & $9.23 \pm 1.62$ & $9.94 \pm 1.34$ & $8.44 \pm 0.95$ \\
Lymphocyte count (thousand $\left./ \mathrm{cm}^{2}\right)$ & $2.82 \pm 0.42$ & $2.58 \pm 0.64$ & 0.061 \\
Protein $(\mathrm{g} / \mathrm{dl})$ & $5.77 \pm 0.15$ & $6.40 \pm 0.19$ & 0.195 \\
Albumin $(\mathrm{g} / \mathrm{dl})$ & $2.94 \pm 0.06$ & $2.63 \pm 0.09$ & $5.18 \pm 0.22$ \\
Serum lactate $(\mathrm{mmol} / \mathrm{l})$ & $2.84 \pm 0.08$ & $3.25 \pm 0.29$ & $2.55 \pm 0.08$ \\
SOFA score & $6.00 \pm 0.12$ & $4.00 \pm 0.31$ & $2.67 \pm 0.11$ \\
\hline
\end{tabular}

Table 3: Comparison of parameters in Group 2

\begin{tabular}{|c|c|c|c|c|}
\hline Variables & Day 1 & Day 4 & Day 7 & $\mathbf{p}$ \\
\hline TLC (thousand $/ \mathrm{cm}^{2}$ ) & $12.61 \pm 1.34$ & $11.18 \pm 1.10$ & $10.10 \pm 1.85$ & 0.834 \\
\hline Lymphocyte count (thousand $/ \mathrm{cm}^{2}$ ) & $2.09 \pm 0.34$ & $1.97 \pm 0.25$ & $2.42 \pm 0.52$ & 0.142 \\
\hline Protein $(\mathrm{g} / \mathrm{dl})$ & $5.56 \pm 0.64$ & $5.55 \pm 0.75$ & $5.64 \pm 0.82$ & 0.422 \\
\hline Albumin (g/dl) & $2.44 \pm 0.04$ & $2.91 \pm 0.06$ & $3.52 \pm 0.09$ & 0.075 \\
\hline Serum lactate (mmol/l) & $2.98 \pm 0.01$ & $2.92 \pm 0.04$ & $2.90 \pm 0.03$ & 0.280 \\
\hline SOFA score & $6.00 \pm 0.15$ & $5.00 \pm 0.19$ & $2.50 \pm 0.12$ & $<0.001$ \\
\hline
\end{tabular}

TLC: Total leukocyte count

Table 4: Comparison of parameters in Group 3

\begin{tabular}{|c|c|c|c|c|}
\hline Variables & Day 1 & Day 4 & Day 7 & $\mathbf{p}$ \\
\hline TLC (thousand $/ \mathrm{cm}^{2}$ ) & $14.97 \pm 1.96$ & $12.84 \pm 1.74$ & $10.49 \pm 1.42$ & 0.035 \\
\hline Lymphocyte count (thousand $/ \mathrm{cm}^{2}$ ) & $1.76 \pm 0.5$ & $1.83 \pm 0.43$ & $2.3 \pm 0.18$ & 0.031 \\
\hline Protein $(\mathrm{g} / \mathrm{dl})$ & $6.10 \pm 0.89$ & $6.00 \pm 0.41$ & $6.17 \pm 0.65$ & 0.045 \\
\hline Albumin (g/dl) & $2.97 \pm 0.02$ & $3.34 \pm 0.06$ & $3.43 \pm 0.09$ & 0.042 \\
\hline Serum lactate $(\mathrm{mmol} / \mathrm{l})$ & $3.05 \pm 0.01$ & $3.07 \pm 0.03$ & $2.97 \pm 0.01$ & 0.04 \\
\hline SOFA score & $6.00 \pm 0.12$ & $4.50 \pm 0.16$ & $2.00 \pm 0.24$ & $<0.001$ \\
\hline
\end{tabular}

TLC: Total leukocyte count

have safely used up to $0.5 \mathrm{~g} / \mathrm{kg} /$ day [13]. Up to $40 \mathrm{~g} /$ day of L-glutamine is safe by combined enteral and parenteral route [14]. Heyland et al. recommended that at least 6 days of parenteral therapy with glutamine in therapeutic dose was required to derive maximum benefit [15]. So in our study, we used a dose of $0.5 \mathrm{~g} / \mathrm{kg} /$ day for a duration of 7 days. Our study resembles the pilot study conducted by Luo et al. with respect to the setting and dosage of glutamine [16]. Day 1 SOFA score is an indicator of the severity of illness. In our study, the day 1 SOFA score median values were same in the three groups. The decrease in SOFA score was statistically significant in the three groups. However, the decrease in SOFA score from day 1 to day 7 was more in Group 3 as compared to 1 and 2. The median SOFA score decreased from 6 to 3.5 in Group 1, 6 to 2.5 in Group 2, and 6 to 2 in Group 3. This indicates an appreciable improvement in disease states in Groups 2 and 3. Our study reflected an increased improvement in SOFA score in the parenteral group than in the entire group which is similar to study by Ferreira et al. [17]. This may be due to the delay in onset of action in the enteral glutamine group which may be due to impaired absorption in the intestinal villi, presence of immature villi, decreased blood flow in the gut, larger utilization by the enterocytes or metabolism by the splanchnic organs. The bioavailability of parenteral glutamine is $100 \%$. This is consistent with the result of Beale et al. [18].

There was no significant change among the three groups with respect to the total leucocytes count, but the change was significant for total lymphocyte count on days 4 and 7 . There was an improvement in lymphocyte count in both Groups 2 and 3 but reached significant levels only Group 3. This is consistent with the result of Fuentes-Orozco et al. who did not observe any different in the total leukocytes count [19]. In our study, there was a significant increase in albumin levels in Group 3 although the Group 2 also showed some improvement in serum albumin. These results correlate well with the study of FuentesOrozco et al. who found an increase in protein and albumin counts in the glutamine-supplemented groups [19]. Ockenga et al. also showed a significant increase in serum albumin in acute pancreatitis patients supplemented with parenteral glutamine. This is particularly important in Indian population who are prone to malnutrition and hypoproteinemia, an important predictor of morbidity and mortality in hospitalized patients [20]. There was no significant change in both intergroup and intragroup comparison in the blood glucose levels in 
our study. There was no significant different in the mortality among the three group. The number of deaths in Group 3 was lesser but was of not statistically significant. The LOS in ICU and duration of mechanical ventilation as predictors of morbidity was not statistically different among the three groups.

This was consistent with the results of the previous studies who studied the effect of glutamine as a nonsignificant predictor of morbidity and mortality [21-26]. A meta-analysis by Oldani et al. analyzing 30 randomized controlled trials (RCTs) with a total of 3696 patients, 1852 receiving glutamine in elective surgical and critically ill patients and showed a moderate reduction in mortality in the parenteral group [27]. Bollhalder et al. also included 11 RCTs and concluded that glutamine given at a dose $>0.2 \mathrm{~g} / \mathrm{kg} /$ day for at least 9 days was associated with a decreased mortality rate, reduced hospital stay, and reduction in infectious complications [28]. Meta-analysis by Chen et al. showed no benefit of glutamine on mortality or LOS although there was a reduction in infections in the infections in the glutamine-supplemented group [29]. Tao et al. showed a low-quality evidence that glutamine reduces the LOS and showed no effect on mortality [30]. Meta-analysis by Kang et al. to assess the effect of glutamine in surgical patients with GI tumors showed improved immune function, reduce infections and shortened the length of ICU stay. Enteral glutamine supplementation does not confer significant benefits in the treatment of critically ill patients [31]. In burned patients, there may be a benefit reducing mortality and infectious morbidity, but data are scarce, and broader studies are warranted to confirm this effect [32]. John and Aanandhi, in their study, have concluded that the supplementation of enteral glutamine in post-operative patients decreases the incidence of post-surgical infection, shortening of hospital stay, and reduction in the overall hospital costs which were similar to our study [33]. Oktavia et al. in a review of many studies in critically ill adults suggested that glutamine-supplemented amino acid solutions may reduce mortality, improve nitrogen balance, and reduce the incidence of clinical infection [34]. Available data on glutamine-supplemented via parenteral nutrition cannot be compared to enteral nutrition supplemented and therefore cannot be used as the basis for recommendation of enteral glutamine administration. Despite this apparent paradigm change, there is sufficient evidence in the literature on the benefits of glutamine that impel us to continue research by putting forth new questions.

\section{CONCLUSION}

Our findings are in contrast to recently published Redox study and Signet study. It is not easy to obtain a clear answer to the above-quoted question, as the critically ill population is a heterogeneous one. Studies often mix patients with different pathologies and prognoses, as well as include distinct routes of administration and the use of different doses than those recommended by the guidelines, thus giving mixed results, especially when compared to a meta-analysis. The effect of parenteral glutamine supplementation on mortality differed with patient population, mode of nutrition, and glutamine dosages. There are differences in subpopulations of ICU patients with a beneficial improvement in the surgical population versus medical or mixed ICU population. Future research must explorer the mechanism by which a glutamine deficiency could be harmful for some patients and bow patients and how to be supplemented both dose and route.

\section{REFERENCES}

1. Sandini M, Nespoli L, Oldani M, Bernasconi DP, Gianotti L. Effect of glutamine dipeptide supplementation on primary outcomes for elective major surgery: Systematic review and meta-analysis. Nutrients 2015;7(1):481-99.

2. Oudemans-van Straaten HM, Bosman RJ, Treskes M, van der Spoel HJ, Zandstra DF. Plasma glutamine depletion and patient outcome in acute ICU admissions. Intensive Care Med 2001;27(1):84-90.

3. Garrel D, Patenaude J, Nedelec B, Samson L, Dorais J, Champoux J, et al. Decreased mortality and infectious morbidity in adult burn patients given enteral glutamine supplements: A prospective, controlled, randomized clinical trial. Crit Care Med 2003;31(10):2444-9.

4. Dechelotte P, Hasselmann M, Cynober L, Allaouchiche B, Coëffier M,
Hecketsweiler B, et al. L-alanyi L-glutamine dipeptide supplemented total parenteral nutrition reduces infectious complications and glucose intolerance in crtitically ill patient: The French controlled, randomized, double blind, multicentre study. Crit Care Med 2006;34(3):598-604.

5. Novak F, Heyland DK, Avenell A, Drover JW, Su X. Glutamine supplementation in serious illness: A systematic review of the evidence. Crit Care Med 2002;30(9):2022-9.

6. McClave SA, Taylor BE, Martindale RG, Warren MM, Johnson DR, Braunschweig C, et al. Guidelines for the provision and assessment of nutrition support therapy in the adult critically ill patient. SCCM and A.S.P.E.N. J Parenter Enteral Nutr 2016;40(2):159-211.

7. Heyland DK, Dhaliwal R, Drover JW, Gramlich L, Dodek P; Canadian Critical Care Clinical Practice Guidelines Committee. Canadian clinical practice guidelines for nutrition support in mechanically ventilated, critically ill adult patients. JPEN J Parenter Enteral Nutr 2003;27(5):355-73.

8. Kreymann KG, Berger MM, Deutz NE, Hiesmayr M, Jolliet P, Kazandjiev $\mathrm{G}$, et al. ESPEN guidelines on enteral nutrition: Intensive care. Clin Nutr 2006;25(2):210-23.

9. Heyland D, Muscedere J, Wischmeyer PE, Cook D, Jones G, Albert M, et al. A randomized trial of glutamine and antioxidants in critically ill patients. N Engl J Med 2013;368(16):1489-97.

10. Andrews PJ, Avenell A, Noble DW, Campbell MK, Croal BL, Simpson WG, et al. Randomised trial of glutamine, selenium, or both, to supplement parenteral nutrition for critically ill patients. Br Med $\mathbf{J}$ 2011;342:d1542.

11. Hall JC, Dobb G, Hall J, de Sousa R, Brennan L, McCauley R. A prospective randomized trial of enternal glutamine in critical illness. Intensive Care Med 2003;29(10):1710-6.

12. Zhou YP, Jiang ZM, Sun YH, Wang XR, Ma EL, Wilmore D. The effect of supplemental enteral glutamine on plasma levels, gut function, and outcome in severe burns: A randomized, double-blind, controlled clinical trial. JPEN J Parenter Enteral Nutr 2003;27(4):241-5.

13. Goeters C, Wenn A, Mertes N, Wempe C, Van Ake H, Stehle P, et al. Parenteral L-alanyl-L-glutamine improves 6 months out come in critically ill patients. Crit Care Med 2002;30(9):2032-7.

14. Wischmeyer PE, Lynch J, Liedel J, Wolfson R, Riehm J, Gottlieb L, et al. Glutamine administration reduces gram-negative bacteremia in severely burned patients: A prospective, randomized, double-blind trial versus isonitrogenous control. Crit Care Med 2001;29(11):2075-80.

15. Heyland DK, Dhaliwal R, Day A, Drover J, Cote H, Wischmeyer P, et al. Optimizing the dose of glutamine dipeptides and antioxidants in critically ill patients: A phase I dose-finding study. J Parenter Enteral Nutr 2007;31(2):109-18.

16. Luo M, Bazargan N, Griffith DP, Estívariz CF, Leader LM, Easley KA, et al. Metabolic effects of enteral versus parenteral alanyl-glutamine dipeptide administration in critically ill patients receiving enteral feeding: A pilot study. Clin Nutr 2008;27(2):297-306.

17. Ferreira FL, Bota DP, Bross A, Mélot C, Vincent JL. Serial evaluation of the SOFA score to predict outcome in critically ill patients. JAMA 2001;286(14):1754-8.

18. Beale RJ, Sherry T, Lei K, Campbell-Stephen L, McCook J, Smith J, et al. Early enteral supplementation with key pharmaconutrients improves Sequential Organ Failure Assessment score in critically ill patients with sepsis: Outcome of a randomized, controlled, doubleblind trial. Crit Care Med 2008;36(1):131-44.

19. Fuentes-Orozco C,Anaya-Prado R, González-OjedaA,Arenas-MárquezH, Cabrera-Pivaral C, Cervantes-Guevara G, et al. L-alanyl-L-glutaminesupplemented parenteral nutrition improves infectious morbidity in secondary peritonitis. Clin Nutr 2004;23(1):13-21.

20. Ockenga J, Borchert K, Rifai K, Mans MP, Bischoff CC. Effect of glutamine-enriched total parenteral nutrition in patients with acute pancreatitis. Clin Nutr 2002;21(5):409-16.

21. Kumar S, Kumar R, Sharma SB, Jain BK. Effect of oral glutamine administration on oxidative stress, morbidity and mortality in critically ill surgical patients. Indian J Gastroenterol 2007;26(2):70-3.

22. Schulman AS, Willcutts KF, Claridge JA, Evans HL, Radigan AE, O'Donnell KB, et al. Does the addition of glutamine to enteral feeds affect patient mortality? Crit Care Med 2005;33(11):2501-6.

23. Griffiths RD, Jones C, Palmer TE. Six-month outcome of critically ill patients given glutamine-supplemented parenteral nutrition. Nutrition 1997;13(4):295-302.

24. Griffiths RD, Allen KD, Andrews FJ, Jones C. Infection, multiple organ failure, and survival in the intensive care unit: Influence of glutaminesupplemented parenteral nutrition on acquired infection. Nutrition 2002;18(7-8):546-52.

25. Xian-Li H, Qing-Ji M, Jian-Guo L, Yan-Kui C, Xi-Lin D. Effect of 
total parenteral nutrition (TPN)with and without glutamine dipeptide supplementation on out come in severe acute pancreatitis (SAP). Clin Nutr Suppl 2004;1(1):43-7.

26. van Zanten AR, Dhaliwal R, Garrel D, Heyland DK. Enteral glutamine supplementation in critically ill patients: A systematic review and metaanalysis. Crit Care 2015;19:294

27. Oldani M, Sandini M, Nespoli L, Coppola S, Bernasconi DP, Gianotti L. Glutamine supplementation in intensive care patients: A meta-analysis of randomized clinical trials. Medicine (Baltimore) 2015;94(31):e1319.

28. Bollhalder L, Pfeil AM, Tomonaga Y, Schwenkglenks M. A systematic literature review and meta-analysis of randomized clinical trials of parenteral glutamine supplementation. Clin Nutr 2013;32(2):213-23.

29. Chen QH, Yang Y, He HL, Xie JF, Cai SX, Liu AR, et al. The effect of glutamine therapy on outcomes in critically ill patients: A meta-analysis of randomized controlled trials. Crit Care 2014;18(1):R8.

30. Tao KM, Li XQ, Yang LQ, Yu WF, Lu ZJ, Sun YM, et al. Glutamine supplementation for critically ill adults. Cochrane Database Syst Rev 2014;9:CD010050

31. Kang K, Shu XL, Zhang YS, Liu XL, Zhao J. Effect of glutamine enriched nutrition support on surgical patients with gastrointestinal tumor: A meta-analysis of randomized controlled trials. Chin Med J (Engl) 2015;128(2):245-51.

32. El-Din AA, Korraa A, Labib H, Salah DD. Studying the effect of parenterally administered L-alanyl L-glutamine dipeptide in diabetes and new onset diabetes in liver transplantation. Egypt J Anaesth 2016;32(3):415-20.

33. John MR, Aanandhi MV. Enteral/oral glutamine supplementation in patients following surgery and accidental injury. Asian J Pharm Clin Res 2017;10(3):477-9.

34. Oktavia SY, Arifin H, Yosmar R. Parenteral nutrition in neonates and compatibility issues: A review article. Asian J Pharm Clin Res 2017;10(2):54-64. 